\title{
APLIKASI CEK BAYAR PAJAK KENDARAAN BERMOTOR SAMSAT JAWA TIMUR BERBASIS ANDORID
}

\author{
Subagiyo ${ }^{1)}$ Muhyiddin Zainul Arifin ${ }^{2)}$ Agus Sifaunajah ${ }^{3)}$ \\ ${ }^{1)}$ Email : bexkuryu@gmail.com \\ ${ }^{2)}$ E-mail : muhyiddin_arifin@yahoo.co.id \\ ${ }^{3)}$ E-mail : agus.syifa85@gmail.com
}

\begin{abstract}
Monopoly check is a monopoly that was taken from the owner and authority vehicle that was registered in their territory. Android is operation system for a mobile phone with the basic linux to reserve opening platform for advance to make their application. The researcher using research method to make the last report is observation with the data to use in his report. Interview with the session asking question for the official samsat gresik to get more detail payment. The researcher are getting reference from the books that can applied in this research.

From the result findings that was the researcher doing, the researcher make "Check Application Of Monopoly Payment Vehicle Through The Basic Android". His research applied counting of monopoly check vehicle into sets agency media android. Besides that tools was used into make application is android studio as IE legality to develop android and java application as language program that was used. For the expectation, into the result finding is to make user of this application they are getting easy to get more information about the payment of monopoly vehicle.
\end{abstract}

Keyword : monopoly, vehicle, java, android 


\section{Pendahuluan}

Subjek atau Wajib Pajak Kendaraan Bermotor adalah orang pribadi atau badan hukum yang memiliki atau menguasai kendaraan bermotor. Wajib pajak melakukan pembayaran pajak kendaraan bermotornya di Kantor Bersama Samsat, dengan syarat yang berbeda-beda sesuai dengan proses yang akan dilalui. Seringkali wajib pajak tidak mengetahui persyaratan yang harus dilengkapi maupun nominal yang dikenakan dalam proses pembayaran pajak kendaraan bermotornya.

Dengan aplikasi cek bayar pajak kendaraan bermotor berbasis android ini wajib pajak dapat mengetahui pengenaan pajak kendaraan bermotornya dan juga dapat menampilkan informasi persyaratan proses-proses pembayaran yang lain seperti ; Pajak 5 tahunan (ganti plat), BBN2 (balik nama), Mutasi keluar, Mutasi masuk, Duplikat STNK.

\section{Kerangka Teori}

\subsection{Landasan Teori}

Pajak Kendaraan Bermotor adalah pajak yang dipungut atas kepemilikan dan penguasaan kendaraan bermotor yang terdaftar di daerah. Kendaraan bermotor adalah semua kendaraan beroda yang digunakan disemua jenis jalan darat, dan digerakkan oleh peralatan teknik berupa motor atau peralatan lainnya yang berfungsi untuk mengubah suatu sumber daya tertentu menjadi tenaga gerak kendaraan bermotor yang bersangkutan, termasuk alat-alat berat dan alatalat besar yang dalam operasinya menggunakan motor dan tidak melekat secara permanen serta kendaraan yang dioperasikan di air.( Dipenda Jatim,2014).

Android adalah sistem operasi yang dikembangkan untuk perangkat mobile berbasis Linux. Pada awalnya sistem operasi ini dikembangkan oleh Android Inc. yang kemudian dibeli oleh Google pada tahun 2005. Dalam usaha mengembangkan Android pada tahun 2007 dibentuklah Open Handset Alliance (OHA) dalam sebuah konsorsium dari beberapa perusahaan, yaitu Texas Instrument, Broadcom Corporation, Google, HTC, Intel , LG, Marvell Technology Group, Motorola, Nvidia, Qualcomm, Samsung Electronics, Sprint Nextel dan T-Mobile dengan tujuan untuk mengembangkan standard terbuka untuk perangkat mobile.( Stephanus,2011)

\section{Metodologi}

\subsection{Alat dan Bahan}

Bahan penelitian yang digunakan dalam proses penelitian ini didapat melalui observasi data di samsat gresik, wawancara kepada petugas untuk mendapatkan rincian pembayaran dan menumpulkan buku yang sesuai sebagai penunjang penelitian.

Dalam melakukan penelitian ini, alat yang digunakan untuk keberhasilan penelitian adalah sebagai berikut :
a. Perangkat Keras
Aspire 4750 : Processor intel@ Core i3-2310M, RAM 4 GB, Harddisk 500 GB
b. Perangkat Mobile
Samsung Galaxy Grand Prime (SM-G531H) : Processor Marvel, PXA1908, Quad Core 1.2
GHz cortex-A53, RAM 1 GB, Memory Internal 8 GB
c. Perangkat Lunak
OS Windows 7 Ultimate 32 bit, Android Studio, Bluestacks , OS Android Lollipop 5.1.1

\subsection{Perancangan Sistem}

Flowchart adalah bagan (chart) yang menunjukkan alir (flow) didalam program atau prosedur sistem logika, sedangkan bagan alir program (flowchart program) merupakan bagan alir yang mirip dengan alir sistem, yaitu untuk mengambarkan prosedur didalam sistem. Berikut adalah flowchart aplikasi dan sistem menu yang diusulkan, dapat dilihat pada gambar 3. 1 dan gambar 3.2. 
1. Flowchart Aplikasi

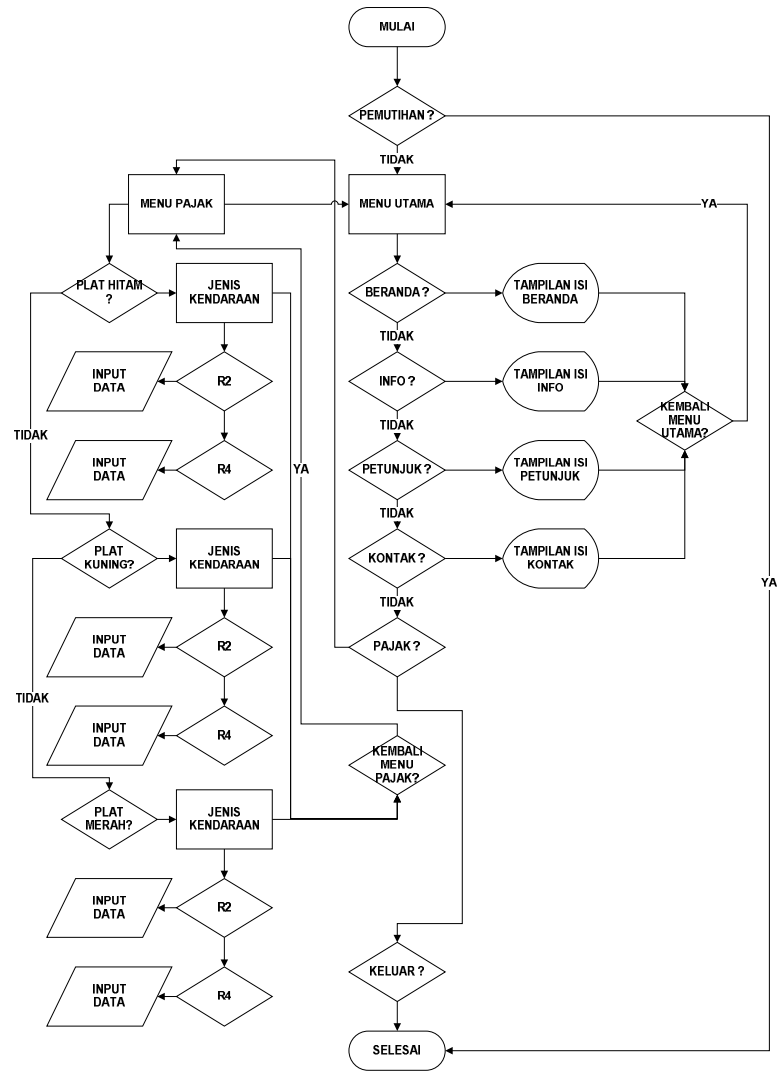

Gambar 3.1 Tampilan Flowchart Aplikasi cek bayar PKB

2. Flowchart Sistem Menu

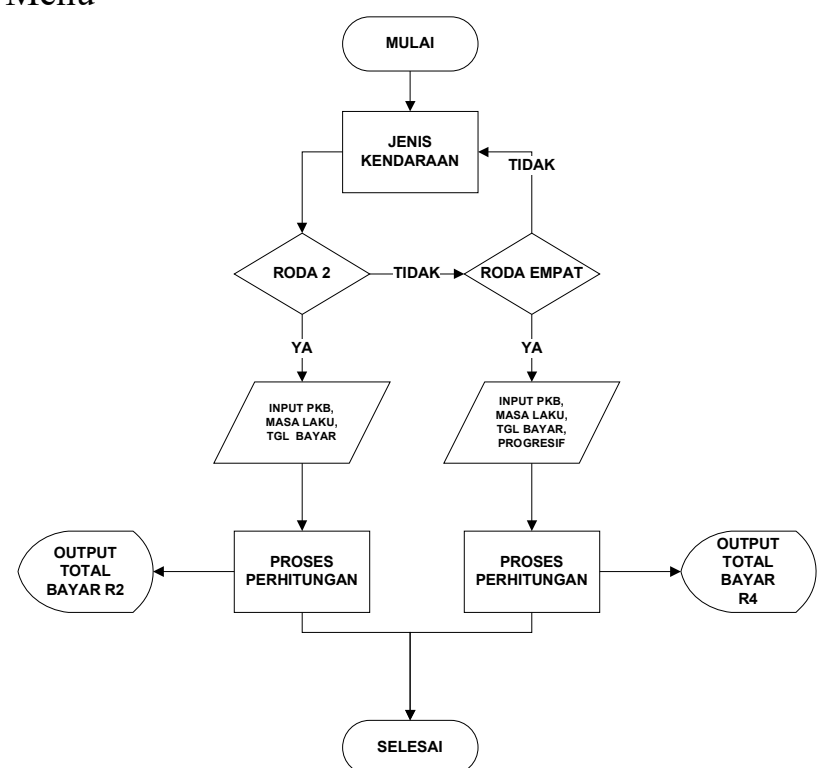

Gambar 3.2 Tampilan Flowchart Sistem menu cek bayar PKB 


\section{Hasil dan Pembahasan}

\subsection{Perancangan Interface Aplikasi}

Perancangan interface aplikasi cek bayar pajak kendaraan bermotor samsat jatim berbasis android ini dibangun dengan bahasa pemrograman java. Adapun sebagai bentuk perancangan yang dibutuhkan adalah sebagai berikut :

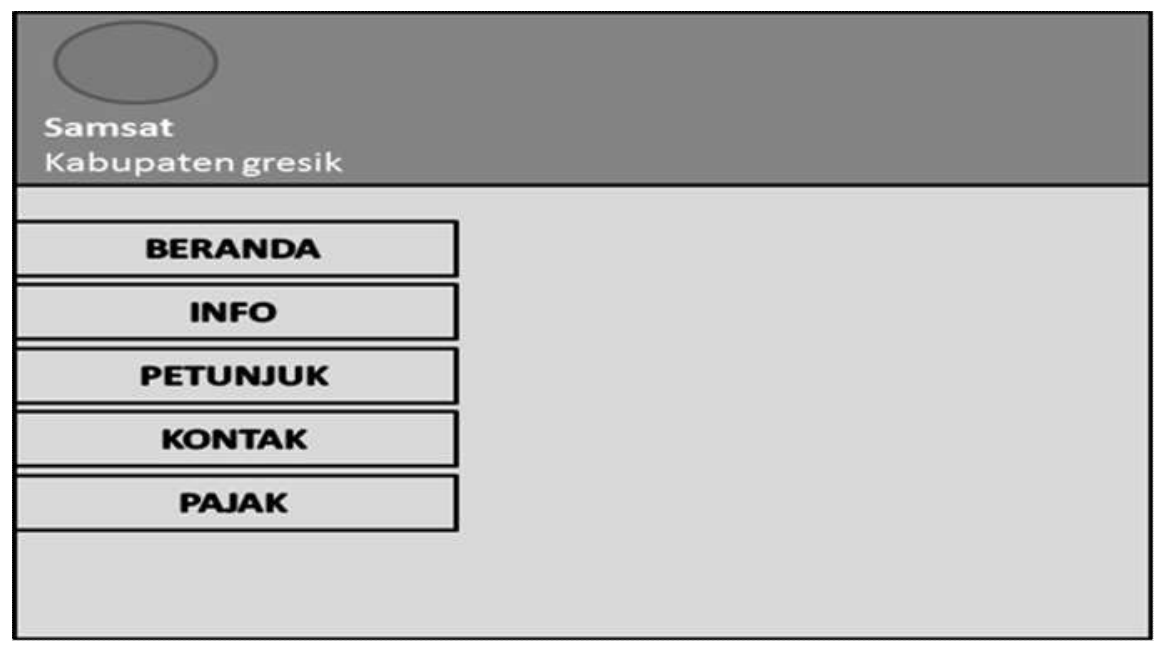

Gambar 4.1 Tampilan Form Menu Utama

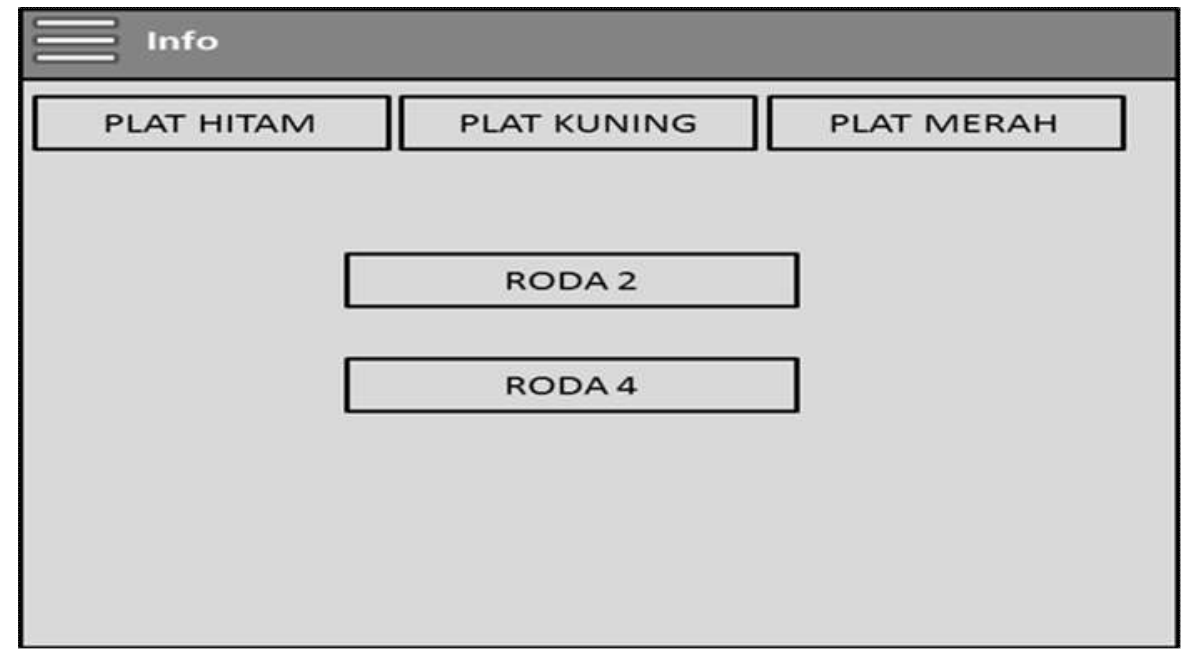

Gambar 4.2 Tampilan Form pajak

\subsection{Hasil Interface Aplikasi}

Setelah dilakukan perancangan interface, dilakukan pengujian untuk melihat apakah hasil perancangan dapat berjalan sesuai harapan. Adapun sebagai hasil yang didapatkan adalah sebagai berikut : 


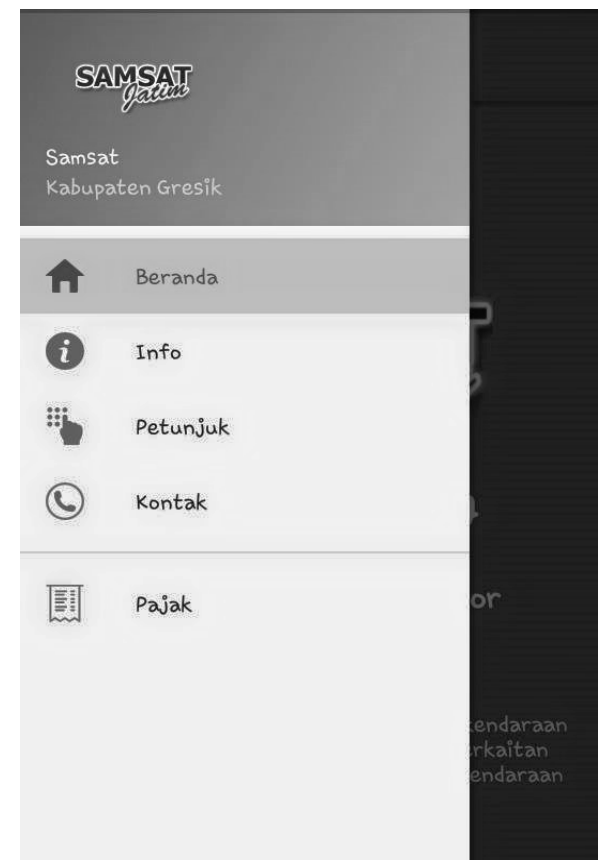

Gambar 4.3 Tampilan Menu Utama Aplikasi
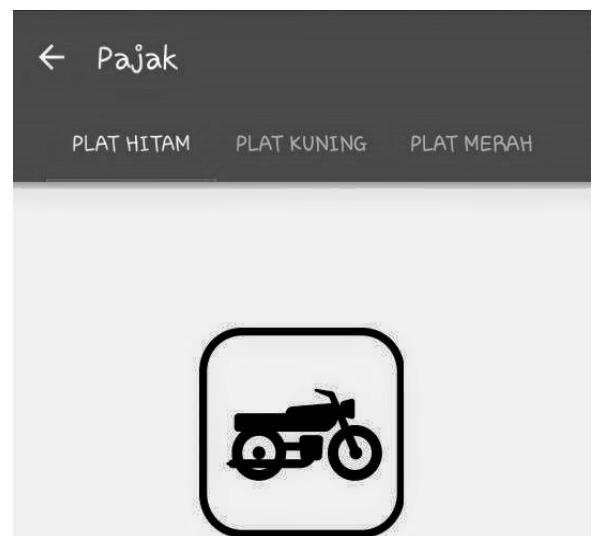

Roda Dua

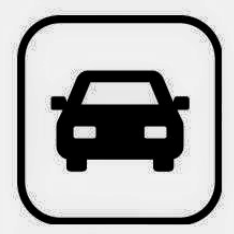

Roda Empat

Gambar 4.4 Tampilan Menu Pajak 


\subsection{Hasil Perhitungan}

Tabel 4.1 Perhitungan Manual Roda Empat

\begin{tabular}{|c|c|c|c|c|c|}
\hline No. & $\begin{array}{c}\text { Nominal } \\
\text { PKB }\end{array}$ & Masa laku & $\begin{array}{c}\text { Tanggal } \\
\text { bayar }\end{array}$ & $\begin{array}{c}\text { Status } \\
\text { progresif } \\
\text { ke- }\end{array}$ & $\begin{array}{c}\text { Total } \\
\text { bayar }\end{array}$ \\
\hline 1. & 1.260 .000 & $08-06-2016$ & $24-05-2016$ & 2 & 1.403 .000 \\
\hline
\end{tabular}

Tabel 4.2 Pengenaan Denda Dan Bunga 2016

\begin{tabular}{|l|l|l|l|l|l|l|l|l|l|l|l|l|}
\hline Tahun & \multicolumn{10}{|c|}{ Bulan } \\
\hline 2016 & jan & feb & mar & apr & mei & jun & jul & ags & sep & okt & nov & des \\
\hline
\end{tabular}

keterangan :

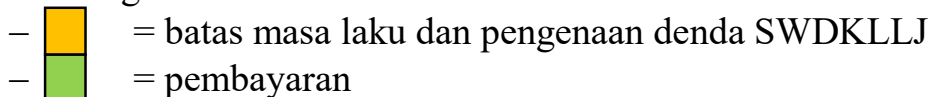

Hitung :

1. $\quad$ Nomininal PKB Notice $=1.260 .000$

2. SWDKLLJ $=143.000$

3. Denda SWDKLLJ $=0$

4. Bunga PKB $=0$

5. Mencari nilai NJKB $=\mathrm{PKB} \div$ (nilai progresif)

$$
\begin{aligned}
& =1.260 .000 \div \frac{2}{100} \\
& =63.000 .000
\end{aligned}
$$

6. Mencari Pokok PKB $=63.000 .000 \times \frac{15}{100}$

$$
=945.000
$$

7. Pajak progresif ke- $2=$ nominal PKB notice - pokok PKB

$$
=1.260 .000-945.000
$$$$
=315.000
$$

8. Total bayar $\quad=1.403 .000$ 


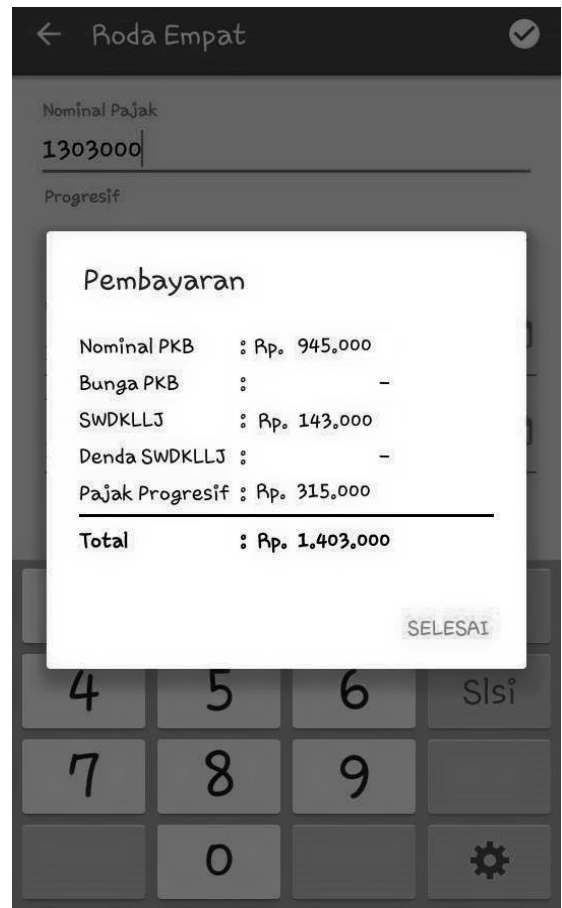

Gambar 4.5 Hasil Perhitungan Roda Empat Menggunakan Aplikasi

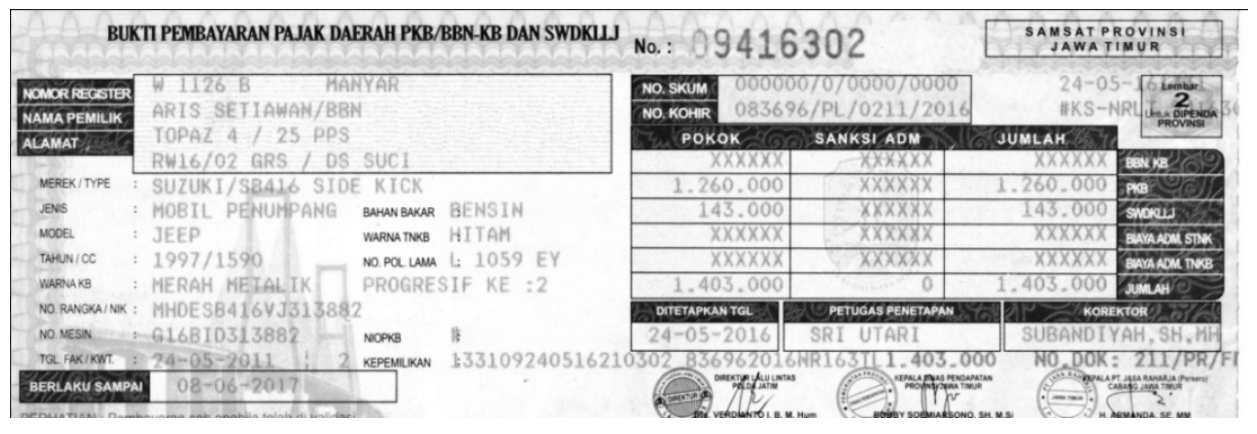

Gambar 4.6 Sample Notice Roda Empat

\section{Penutup}

\subsection{Kesimpulan}

Kesimpulan yang dapat diambil dari hasil analisa dan pengujian dari aplikasi cek bayar pajak kendaraan bermotor yang sudah dibangun adalah:

1. Aplikasi ini sebagai alat bantu dalam menentukan perhitungan pengenaan pajak kendaraan bermotor, sehingga diharapkan pengguna dapat mendapat rincian pajak kendaraan bermotor secara jelas dan akurat.

2. Aplikasi ini memberikan informasi persyaratan dari berbagai macam pembayaran yang ada di kantor bersama samsat, sehingga diharapkan pengguna dapat memahami dan melengkapi persyaratan tersebut sebelum dating ke kantor bersama samsat.

3. Tampilan antarmuka aplikasi yang mudah dipahami dan dijalankan oleh pengguna, sehingga diharapkan akan memberikan kemudahan terkait pemberian informasi dan perhitungan pajak kendaraan bermotor. 


\subsection{Saran} berikut:

Adapun saran-saran untuk pengembangan dan perbaikan aplikasi ini adalah sebagai

1. Diharapkan aplikasi ini kedepannya dapat melakukan perhitungan pengenaan Bea Balik Nama 2 (BBN2), sehingga dapat memberikan informasi yang lebih lengkap.

2. Diharapkan aplikasi ini kedepannya dapat memberikan informasi tambahan terkait persyatan pengurusan kendaraan baru, sehingga dapat memberikan informasi yang lebih lengkap.

3. Diharapkan aplikasi ini kedepannya dapat berjalan maksimal pada spesifikasi yang lebih rendah, karena kebutuhan ekonomi yang semakin meningkat dan mungkin anak-anak hanya dapat memiliki sebuah perangkat mobile android yang memliki spesifikasi dibawah gingerbread.

\section{Daftar Pustaka}

Dipenda Jatim.2014. "Bimbingan Teknis PNS \& PTT Dinas Pendapatan Provinsi Jawa Timur Tahun 2014". Surabaya : Dipenda Jatim.

Hariyanto, Bambang. 2005. “Esensi-esensi Bahasa Pemrograman Java”. Bandung :

Informatika Bandung.

Jogiyanto. 2005. "Analisis dan Desain Sistem Informasi”. Yogyakarta : Andi.

Safaat H, Nazruddin.2011. "Pemrograman Aplikasi Mobile Smartphone Dan Tablet PC Berbasis Android". Bandung: Informatika Bandung.

Stephanus.2011."Mudah Membuat Aplikasi Android". Salatiga : Andi. 